\title{
PRIVAÇÃO DE ESCOLARIDADE: A SITUAÇÃO DO JOVEM EM CONFLITO COM A LEI E A ESCOLARIZAÇÃO
}

\author{
Riane Conceição Ferreira FREITAS ${ }^{1}$ \\ Universidade Federal do Pará - UFPA \\ rianecffretas@hotmail.com \\ Gilmar Pereira da SILVA ${ }^{2}$ \\ Universidade Federal do Pará - UFPA \\ gpsilva@ufpa.br
}

Resumo: Este artigo tem como objetivo desvelar como se redefinem, na atualidade, as políticas educacionais para o jovem que cometeu ato infracional e cumpre medida socioeducativa privado de liberdade em uma Unidade de Internação. Por meio de pesquisa documental, analisamos os relatórios oficiais que revelam a escolarização ou não-escolarização desses jovens no período de cumprimento da medida. Temos como referência teórico-metodológica o materialismo histórico-dialético. Nossos apontamentos conclusivos indicam que esse modelo atual de ressocialização tem pouca efetividade para a reinserção do jovem após o período de internação do cumprimento de medida socioeducativa.

Palavras-chave: Jovem em conflito com a lei; Medida Socioeducativa; Política Educacional.

\begin{abstract}
This article aims to reveal how are redefined the current educational policies for the young person who committed an offense and is serving a socio-educational and freedomdepriving sentence in a confinement unity. Through documentary research, we analyzed the official reports which reveal the promotion of schooling or non-schooling to these young people in the period serving the measure. Our theoretical and methodological reference is historicaldialectical materialism. Our conclusions indicate that the current model of rehabilitation has little effectiveness for the reintegration of the young person after the confinement period for the fulfillment of socio-educational measures.
\end{abstract}

Keywords: Youth in conflict with the law. Socioeducational Measure. Educational Policy.

\footnotetext{
${ }^{1}$ Doutoranda em Educação pela Universidade Federal do Pará (2013-2017). Mestra em Educação pela Universidade Federal do Pará (2012). Coordenadora de Área do Programa de Iniciação à Docência/PIBID/UFPA/PEDAGOGIABELÉM; Especialista em Psicopedagogia (2007) pela FACET. Graduada em Pedagogia pela UFPA. Atualmente é pesquisadora da UFPA e membro do Grupo de Estudo e Pesquisa sobre Trabalho e Educação - GEPTE/ICED/UFPA.

${ }^{2}$ Possui Doutorado em Educação pela Universidade Federal do Rio Grande do Norte (2005); Mestrado em Educação pela Universidade Federal do Rio Grande do Norte (2002); Especialização em História da Amazônia pela Universidade Federal do Pará (1993) e graduação em Pedagogia pela Universidade Federal do Pará (1992). Atualmente é Professor Associado Il e vice-reitor da Universidade Federal do Pará. Atua no Programa de Pós-Graduação em Educação - PPGED (Mestrado e Doutorado) do Instituto de Ciências da Educação da UFPA e no Programa de Pós-Graduação em Educação e Cultura-PPGEDUC (Mestrado) do Campus de Cametá.
} 


\section{Para início de conversa}

Nossa opção em analisar a situação das políticas educacionais para o jovem que cometeu ato infracional decorre de nossa pesquisa de doutorado, que tem como temática a relação Trabalho e Educação do jovem em conflito com a lei. Neste artigo, objetivamos analisar os dados educacionais dos jovens que cumprem medida socieducativa privados de liberdade.

Vale ressaltar que utilizamos alguns conceitos constantes no documento expedido pela Organização das Nações Unidas em 1985, que estabeleceu regras basilares de proteção à criança e ao adolescente para todos os países, intitulado Regras Mínimas das Nações Unidas para a administração da justiça, da infância e da juventude - Regras de Beinjing, que o Brasil recepcionou na Constituição Federal de 1988 e que, posteriormente, orientaram e sustentaram o Estatuto da Criança e Adolescente - ECA (Lei 8.069/1990), dentre as quais destacam-se:

a) Jovem é toda a criança ou adolescente que, de acordo com o sistema jurídico respectivo, pode responder por uma infração de forma diferente do adulto;

b) Infração é todo comportamento (ação ou omissão) penalizado com a lei, de acordo com o respectivo sistema jurídico;

c) Jovem infrator é aquele a quem se tenha imputado o cometimento de uma infração ou que seja considerado culpado do cometimento de uma infração (VOLPI, 2014, p. 94).

Assim, a medida socieducativa surge no ECA como meio de reorientar o indivíduo submetido a ela, de modo a oportunizar a reparação dos danos e promoção de processos formativoseducacionais ao jovem que infligiu a lei.

De acordo com o Art. 112 do ECA, que dispõe sobre as Medidas Socioeducativas, a autoridade competente poderá aplicar ao adolescente as seguintes penalidades:

I - advertência;

II - obrigação de reparar o dano;

III - prestação de serviço à comunidade;

IV - liberdade assistida;

$\mathrm{V}$ - inserção em regime de semiliberdade;

VI - internação em estabelecimento educacional;

VII - qualquer um das previstas no art. 101, I a VI (BRASIL, 1990, s/n, grifo nosso).

Os incisos V e VI, que tratam do regime de semiliberdade e internação, respectivamente, mencionam a responsabilidade pelos órgãos de garantia de direitos da criança e do adolescente 
sobre a educação e a profissionalização. Apesar de a liberdade assistida prever a supervisão da frequência do acompanhamento escolar e da profissionalização do assistido, é no regime de semiliberdade e internação que a atividades escolares e profissionalizantes passam a ser obrigatórias.

O Art. 120 do ECA, que trata "Do Regime de Semiliberdade", dispõe que "São obrigatórias a escolarização e a profissionalização, devendo, sempre que possível, ser utilizados os recursos existentes na comunidade". Já quando há o cometimento de um ato infracional realizado mediante grave ameaça ou violência à pessoa, ou por atos como a reiteração de outras infrações graves ou o descumprimento de medidas anteriormente impostas que necessite de internação privativa da liberdade (que tem duração máxima de três anos e liberação compulsória aos 21 anos de idade), o jovem também tem o direito de "receber escolarização e profissionalização" (BRASIL, 1990).

Vale ressaltar que o termo utilizado pelo ECA para a instituição que acolherá o interno é de "estabelecimento educacional", tentando a letra da lei tornar esse tempo de recolhimento um período de promoção do processo educativo e de responsabilização para a vida em sociedade, de modo a evitar a reinfração destes jovens em conflito com a lei.

Nesse sentido, a medida socieducativa tem duas finalidades: a de sanção da conduta infratora ou ilícita, conforme determina a lei; e a de perspectiva sócio-pedagógica, para o Estado oportunizar a esses jovens a reestruturação de uma nova prática social e educacional, constituindo um aparato governamental tendo todos os poderes e esferas públicas (União, Estados, Municípios, Executivo, Legislativo e Judiciário), além da sociedade civil, comprometidos com o Sistema de Garantia de Direitos (SGD), uma vez que a Educação como dever do Estado está prevista tanto na Constituição Federal quanto em outras leis (a exemplo do ECA) e de tratados internacionais dos quais o Brasil é signatário.

Em 2012, no contexto de delineação das políticas de atendimento à infância e à juventude, foi instituído o Sistema Nacional de Atendimento Socioeducativo - SINASE, Lei n 12.594/2012. O SINASE,

é o conjunto ordenado de princípios, regras e critérios que envolvem a execução de medidas socieducativas, incluindo-se nele, por adesão, os sistemas estaduais, distrital e municipais, bem como todos os planos, político e programas específicos de atendimento a adolescente em conflito com a lei (BRASIL, 2012, s/n). 
Lei do SINASE regulamenta todo o atendimento socioeducativo para crianças e adolescentes com mais de 12 anos e menos de 18 anos de idade que tenham comentido algum ato infracional, além de dar as disposições gerais sobre a instalação, manutenção das unidades e programas de atendimento, ressaltando a competência da União, Estados e Municípios.

No que se refere ao financiamento, o SINASE deverá ser cofinanciado, além de pelos entes federados que instituíram o sistema socioeducativo, também pelo Fundo da Criança e do Adolescente (nas três esferas), pelo Fundo de Prevenção, Recuperação e de Combate às Drogas de abuso (Funcab), pelo Fundo de Amparo ao Trabalhador (FAT) e Fundo Nacional do Desenvolvimento da Educação (FNDE), este último desde que o ente federado que solicitou o recurso tenha assinado o Plano de Metas Compromisso Todos Pela Educação e elaborado o respectivo Plano de Ações Articuladas (PAR).

Estes dispositivos legais são um avanço para a sociedade democrática, pois obriga o Estado a se responsabilizar pelas políticas para a criança e o adolescente, além de determinar de onde vêm os recursos.

É importante observamos que, com a instituição do SINASE, podemos perceber as relações entre trabalho e educação andando lado a lado, tanto com a destinação de recursos do FAT quanto do FNDE, uma vez que, como já vimos anteriormente, a educação escolar para o jovem privado de liberdade está sempre ligada à questão da educação profissional.

\section{De que realidade e de quem estamos falando?}

Dados de um relatório realizado pela Comissão de Infância e Juventude do Conselho Nacional do Ministério Público, denominado "Um Olhar Mais Atento às Unidades de Internação e de Semiliberdade para Adolescentes", realizado por meio de inspeções nas unidades de internação e de semiliberdade em 2013 registraram a presença de 20.081 adolescentes em cumprimento de medidas de privação de liberdade. Destes, 18.378 cumprem medida socioeducativa de internação (provisória, definitiva e internação-sanção), enquanto 1.703 estão no regime da semiliberdade.

Os dados revelam que 95\% desses jovens são do sexo masculino, a maioria deles (cerca de 70\%) têm entre 16 e 18 anos. O segundo grupo mais numeroso é de meninos entre os 12 aos 15 anos de idade. O relatório compara o perfil dos jovens com os dados de evasão escolar da Síntese de Indicadores Sociais, divulgada em 2010 pelo IBGE, para mostrar a relação entre os dois 
indicadores - ou seja, a faixa etária com maior índice de evasão escolar é também a que apresenta maior número de internos nos sistemas de internação e de semiliberdade (16 a 18 anos). De acordo com Frigotto (2004, p. 182), há

um número significativo de jovens das grandes capitais violentados em seu meio e em suas condições de vida, que se enquadram numa situação que, no mundo da física, se denomina de ponto de não-reversibilidade. Trata-se de grupos de jovens que foram tão desumanizados e socialmente violentados que se tornam presas fáceis do mercado da prostituição infanto-juvenil ou de gangues que nada têm a perder ou constituem um exército de soldados do tráfico.

A relação entre juventude, criminalidade, judicialização da vida, educação e trabalho são sobredetermindas pela relação entre o direito e o modo de produção da sociedade na qual estão inseridos esses jovens. Nesse sentido, a articulação entre neoliberalismo e reestruturação produtiva, no contexto da reorganização contemporânea do capital, aumentam dramaticamente os níveis de desemprego e de subemprego no mundo, levando um enorme contingente de trabalhadores à condição de massa popular destituída das bases sociais indispensáveis para sua reprodução. É essa massa popular que será especialmente afetada pelas políticas de encolhimento do aparato social do Estado, por um lado, e pelo recrudescimento da exploração da força de trabalho, de outro. Dando origem ao que alguns autores denominam de "classes perigosas" (JINKINGS, 2010, p.3).

De acordo Scheinvar (et. all, 2014, p. 162),

estar em "perigo" é uma forma de afirmar a necessidade de proteção na construção de um futuro, abrindo a possibilidade de uma vida segura. Já "ser perigoso" é uma indicação de controle, não das condições de vida, mas da pessoa, do seu corpo. Quem está em perigo, tem que ser acudido; quem é perigoso, tem que ser controlado e/ou eliminado.

Há teóricos como Loïc Wacquant (2001) que analisam a estrutura repressora do Estado, dirigida prioritariamente às comunidades consideradas mais "propensas" ao crime, ou seja, as populações que têm uma inserção precarizada no mercado de trabalho e se encontram fora da cada vez mais reduzida rede de proteção estatal. Já Giorgi (2006, p. 28), que analisa o período fordista e o pós-fordista, afirma que, a partir de 1970, passamos a ter o período da "economia política da pena", em que são os pobres, os desempregados, os mendigos e os migrantes as novas "classes 
perigosas" que devem ser individualizadas e separadas da força de trabalho. Portanto, o objetivo do sistema de controle passou a ser o de "neutralizar a 'periculosidade' das 'classes perigosas' através de técnicas de prevenção do risco, que se articulam principalmente sob as formas de vigilância, segregação urbana e contenção carcerária”.

Esses estudos mostram como segmentos sociais precarizados, destituídos de capital, principalmente durante a vigência do Estado fordistakeynesiano, deu lugar não só ao fortalecimento do aparelho prisional estatal, mas também à forte vigilância sobre as denominadas “classes perigosas", por meio da utilização do aparato de proteção social do governo, que, desse modo, torna-se menos focalizado na proteção da pobreza e mais voltado ao seu controle.

A desproporcional dilatação destas "classes perigosas" traz, portanto, como principal consequência a formação de um exército de excluídos do capital. Com efeito, é justamente buscando "reprimir a gigantesca massa de miseráveis criada pela reestruturação contemporânea do capital, que o Estado fortalece ainda mais seu aparelho de coerção, com o objetivo final de manutenção da ordem social" (JINKINGS, 2010, 129) e os jovens estão cada vez mais aumentando os índices nos cárceres.

Este é o quadro no qual se constitui a relação entre aparelho coercitivo estatal e pobreza, sob a vigência do neoliberalismo, que tem reflexo nos altos índices de violência. Dados do Mapa da Violência de 2014/Jovens do Brasil (WAISELFISZ, 2014), por meio de estudos históricos realizados em São Paulo e Rio de Janeiro, evidenciam que as epidemias e doenças infecciosas eram as principais causas de morte entre os jovens cinco ou seis décadas atrás. Já na década atual, estas causas foram progressivamente substituídas pelas denominadas causas externas, principalmente acidentes de trânsito e homicídios. Em 1980, 50\% das mortes dos jovens eram de causas externa. Já em 2012 essa taxa passou para 71,1\%, sendo o Brasil, de acordo com a Organização Mundial da Saúde (OMS), o $8^{\circ}$ país com maior taxa de homicídios (por 100 mil habitantes) na População Jovem

Em 1845, em sua análise sobre a situação da classe trabalhadora na Inglaterra, Engels escreveu que a "delinquência acompanhou a expansão da indústria e que, a cada ano, há uma relação direta entre o número de prisões e o de fardos de algodão consumidos" (p. 248), afirmando que a revolta dos operários contra a burguesia seguiu de perto o desenvolvimento da indústria e atravessou diversas fases, sendo o crime a forma mais estéril e brutal da revolta. 
O próprio Engels afirmou que a hostilidade ao proletariado está na base do ordenamento jurídico, pois “as leis são necessárias porque existem os despossuídos” e sempre está a favor dos interesses do burguês. Sobre isso, Engels considerou:

claro que, para o burguês, a lei é sagrada: trata-se de obra sua, votada com sua concordância, produzida para protegê-lo e garantir seus privilégios; ele sabe que, embora uma lei singular possa prejudicá-lo eventualmente, o conjunto de legislação assegura seus interesses e sabe, sobretudo, que o caráter sagrado da lei, a intangibilidade da ordem social consagrada pela participação ativa da vontade de uma parte da sociedade e pela passividade da outra, é o sustentáculo mais poderoso de sua posição social. O burguês encontra-se a si mesmo na lei, como se encontra em seu próprio deus - por isso ele a considera sagrada (1845, p. 312).

Os dados oficiais trazem números alarmantes no que se refere ao encarceramento de pessoas. "As prisões evidenciam-se como instrumento privilegiado de repressão no aparato coercitivo estatal desde as origens do capitalismo, no neoliberalismo atinge-se o ápice no emprego do aprisionamento de massa como política pública de gestão da pobreza” (JINKINGS, 2010, p. 3), em uma lógica desumanizadora do capital, sendo o Brasil o $4^{\circ}$ país com a maior população prisional no mundo (574,207 mil pessoas), ocupando o $1^{\circ}$ lugar entre os países da América do Sul, de acordo com o Mapa do Encarceramento: Os jovens do Brasil, publicado em 2014 pela Presidência da República.

De acordo com o Mapa do Encarceramento, podemos observar as duas “pontas” da situação da juventude que inflige a lei: um que fez isso entre os 12 aos 18 anos que vai cumprir medida socioeducativa em uma unidade "educacional", e a outra, após completar os 18 anos, que vai para as prisões. Nesse sentido, a população prisional brasileira aumentou, em números absolutos, em 74\% entre os anos de 2005 a 2012, sendo que, no ano de 2004, mais de 3 milhões de brasileiros saíram da miséria, e, em 2005, 7 milhões de brasileiros subiram para a classe média, segundo a Fundação Getúlio Vargas (O GLOBO, 2006), confirmando a tese de Engels levantada em 1945, isto é, crescimento econômico não significa desenvolvimento social. É a "incorrigibilidade da lógica perversa do capital", como refere Mèszàros (2002, p. 34), características de um sistema capitalista tardio, que exauriu a sua capacidade civilizatória e agora, para manter-se, destrói os direitos sociais historicamente conquistados e o meio ambiente. 
Essas políticas de encarceramento da população atingem principalmente a população masculina (84\%), pouco escolarizadas (45\% não completaram o ensino fundamental) e, em sua maioria, composta por jovens de 18 a 24 anos, sendo que os presos de idade entre os 18 aos 29 anos atingiram 54\% no ano de 2012. Apesar do crescimento da população carcerária nas faixas etárias mais velhas, a população presa continua sendo a jovem. No que se refere aos dados de cor e raça, os bancos de dados sempre são muito precários, contudo, de acordo com as informações do Sistema Integrado de Informações Penitenciárias - InfoPen ${ }^{3}$, no ano de 2012, cerca de 60,8\% da população carcerária era de negros (pretos e pardos). Na contramão, no que se refere à cor dos homicídios no Brasil, o Mapa da Violência no Brasil/Homicídios e Juventude no Brasil, mostra

uma acentuada tendência de queda no número de homicídios da população branca e de aumento no número de vítimas na população negra. Essa tendência se observa tanto para o conjunto da população quanto para a população jovem" [...] Assim, o índice de vitimização de jovens negros, que em 2002 era de 79,9, sobe para 168,6: para cada jovem branco que morre assassinado, morrem 2,7 jovens negros. Mas persiste entre os jovens o fato de que os significativos incrementos nos índices de vitimização negra podem ser atribuídos mais às quedas nos homicídios brancos do que a incrementos nos assassinatos de negros (WAISELFISZ, 2013, p. 87).

Vale ressaltar que, historicamente, no Brasil, há um trabalho ideológico no sentido do embranquecimento da população, uma vez que a população autodeclarada branca é de 78,5\% na região Sul, sendo 3,6\% a população preta; já a região nordeste é a que mais se autodeclara preta, com $8,1 \%$, predominando nesta a população parda, com $62,7 \%$ no Norte e $71,2 \%$ no Nordeste, de acordo com o censo do IBGE de 2010. Podemos depreender, concordando com Frigotto (2004, p. 88), que o

preconceito com os negros e os jovens negros, do ponto de vista da criminalidade, está mais do que caracterizado na sociedade brasileira. Embora esteja havendo uma maior conscientização, fruto da organização crescente do movimento negro, as instituições jurídicas e a própria imprensa exigem apuração dos fatos quando eles acontecem com negros famosos.

Assim, os dados mostram no Brasil que o jovem que mais está morrendo compõe a minoria da população e tem uma cor, a preta. Assim como os negros (pretos e pardos) são os que mais

\footnotetext{
${ }^{3} \mathrm{O}$ InfoPen é um programa de computador (software) de coleta de dados do Sistema Penitenciário no Brasil.
} 
morrem, são eles também que formam a maior população carcerária. Essas classificações não são inocentes, assim como a omissão de dados sobre a renda tanto no Mapa da Violência quanto no Panorama Nacional de Execução das Medidas Socioeducativas de Internação, do CNJ e nos relatórios do Ministério Público. Contudo, em uma pesquisa realizada em 2003 pelo IPEA (Instituto de Pesquisa Econômica Aplicada) e Ministério da Justiça, 66\% desses jovens viviam em famílias extremamente pobres.

Nesse sentido, os dados revelam que o encarceramento brasileiro incide sobre homens, negros, jovens e pobres, que, em sua maioria, não completaram o ensino fundamental e o médio, evidenciando uma política de encarceramento de classes, numa lógica desumanizadora.

Vale ressaltar que nossa pesquisa é com os jovens cumpridores de medidas socioeducativas. Optamos por analisar os jovens especialmente porque (de acordo com o Relatório do Panorama Nacional - A execução das Medidas Socioeducativas de Internação Programa Justiça Jovem (BRASIL, 2012), do Conselho Nacional de Justiça) o jovem em privação da liberdade que está cumprindo a medida socioeducativa no Brasil tem em média 16,7 anos, sendo esta a maior faixa etária do cometimento do primeiro ato infracional, período que, de acordo com a Lei de Diretrizes e Bases da Educação Nacional (Lei 9394/2006), o jovem deveria está terminando o ensino médio, etapa final da educação básica, que tem como finalidades:

I - a consolidação e o aprofundamento dos conhecimentos adquiridos no ensino fundamental, possibilitando o prosseguimento de estudos; II - a preparação básica para o trabalho e a cidadania do educando, para continuar aprendendo, de modo a ser capaz de se adaptar com flexibilidade a novas condições de ocupação ou aperfeiçoamento posteriores; III - o aprimoramento do educando como pessoa humana, incluindo a formação ética e o desenvolvimento da autonomia intelectual e do pensamento crítico; IV - a compreensão dos fundamentos científico-tecnológicos dos processos produtivos, relacionando a teoria com a prática, no ensino de cada disciplina (BRASIL, 1996).

Os dados do mesmo relatório informam que $57 \%$ dos jovens não frequentavam a escola antes de ingressar na unidade, $86 \%$ dos adolescentes informaram que cursavam o ensino fundamental, sendo que a média percentual dos adolescentes cumpridores de medida socioeducativa não alfabetizados atingiu o índice de $8 \%$. No entanto, este índice nacional comporta uma disparidade entre as regiões, considerando que no Nordeste $20 \%$ dos adolescentes entrevistados declararam-se analfabetos e no Norte, $14 \%$, enquanto no Sul e no Centro-Oeste, $1 \%$. 
As regiões Norte e Nordeste também possuem o menor índice de internos que concluíram o Ensino

Médio, sendo o índice de $4 \%$ e $6 \%$, respectivamente. No contexto nacional, entre todos os adolescentes analfabetos, $44 \%$ destes se encontram na Região Nordeste. Sendo que as regiões Norte e Nordeste estão abaixo da média nacional de adolescentes que pararam os estudos aos 14 anos, conforme dados do Relatório do Panorama Nacional - A execução das Medidas Socioeducativas de Internação Programa Justiça Jovem (BRASIL, 2012).

O próprio ECA determina que, no período de cumprimento das medidas socioeducativas, tanto no regime de semiliberdade quanto no de internação, deve ser garantido a escolarização e a profissionalização. Contudo, verifica-se que estes dispositivos legais não estão sendo respeitados. $\mathrm{O}$ mesmo relatório do $\mathrm{CNJ}$ comprova que, em regiões brasileiras com expressiva quantidade de adolescentes internos maiores de 18 anos, há um histórico de evasão escolar em torno de $42 \%$. Desse modo, a adoção de medidas mais adequadas de escolarização nos estabelecimentos com uma proposta pedagógica consolidada que possibilite ao jovem ter condições favoráveis que possibilite a ele, ao sair da internação, ter garantida uma reinserção social real parece ser um grande problema.

Este problema pode ser refletido no resultado do relatório do Conselho Nacional de Justiça (CNJ), denominado Panorama Nacional: a execução das Medidas Socioeducativas de Internação (BRASIL, 2012), demonstrando o alto índice de reincidência de infrações dos jovens (em torno de $54 \%$ ). Os crimes das reincidências são mais graves, ou seja, na internação de reincidência, há maior ocorrência de atos infracionais resultantes da morte da vítima, o que demonstra que o objetivo de "ressocializar" e "reeducar" o jovem que conflitou a lei, conforme propõe o Estatuto da Criança e Adolescente (ECA) em seu art. 112, não está sendo efetivado neste sistema punitivo.

Diante desse contexto, é notória a necessidade de aprimoramento do sistema de justiça para que a sociedade e o Estado ofereçam não apenas uma resposta monolítica às situações geradoras de conflitos, mas disponha de outros sistemas, com outras respostas que pareçam mais adequadas diante da complexidade do fenômeno criminal, em que há a exclusão de direitos, e que, "no contexto da mundialização do capital, assumem uma magnitude e uma gravidade sem precedentes" (FRIGOTTO, 2010).

Nicos Poulantzas (1980, p. 33) afirmou que o Estado tem um papel essencial nas "relações de produção e na delimitação-reprodução das classes sociais, porque não se limita ao exercício da repressão física organizada. O Estado também tem um papel específico na organização das relações 
ideológicas e da ideologia dominante". E o direito tem importância fundamental na sociedade de classes, pois ele legitima as relações de produção na sociedade capitalista, tendo a ideologia a função de "organizar um consenso de certas classes e parcelas dominadas em relação ao poder público. A ideologia dominante consiste essencialmente num poder essencial da classe dominante (ibid.)". Nesse caso, o Poder Judiciário, sendo um dos aparelhos ideológicos e repressivo do Estado, tem por função elaborar e reproduzir esta ideologia e a divisão social do trabalho. Vale lembrar que a "ideologia dominante intervém na organização dos aparelhos aos quais compete principalmente o exercício da violência física legítima (exército, polícia, justiça-prisão, administração) " (id., 1980, p. 34).

Essas 'engrenagens' colaboram para que as prisões (tanto para o jovem quanto para o adulto) sejam essenciais ao bom funcionamento do capitalismo. Visto que elas segregam fisicamente os internos e usa de intimidação, visando disciplinar os que se mantêm fora dela, mas podem tornar-se uma ameaça à ordem constituída, convertendo-se em um paradigma de um novo modelo de gestão da miséria, que busca criminalizar comportamentos típicos das classes depauperadas.

\section{Para concluir...}

Consideramos que é notória a necessidade de aprimoramento do sistema de justiça para que a sociedade e o Estado ofereçam não apenas uma resposta monolítica às situações geradoras de conflitos, mas disponham de outros sistemas, com outras respostas que pareçam mais adequadas diante da complexidade do fenômeno criminal e da descriminalização da miséria. Porque, de acordo com os dados apresentados, pouco se tem feito de forma a garantir um processo ressocializador e educativo para quem conflita a lei.

\section{Referências}

BRASIL. Lei 8.069/1990. Estatuto da Criança e do adolescente. Brasília, 1990.

CONSELHO NACIONAL DO MINISTÉRIO PÚBLICO. Relatório da Infância e Juventude Resolução $n^{\circ}$ 67/2011: Um olhar mais atento às unidades de internação e semiliberdade para adolescentes. Brasília, 2013. 
CONSELHO NACIONAL DE JUSTIÇA. Panorama Nacional. A execução das Medidas Socioeducativas de Internação. Programa Justiça Jovem. Brasília, CNJ, 2012.

FRIGOTTO, Gaudêncio. Juventude, Trabalho e Educação no Brasil: Perplexidades, desafios e perspectivas. In: Regina Novaes e Paulo Vannuchi (orgs.), Juventude e sociedade: trabalho, educação, cultura e participação. São Paulo, Fundação Perseu Abramo/Instituto Cidadania, 2004.

GIORGI, Alessandro De. A miséria governada através do sistema penal. Trad. Sérgio Lamarão. Rio de Janeiro: Instituto Carioca de Criminologia; Revan, 2006.

JINKINGS, Isabella. Sob o domínio do medo: controle social e criminalização da miséria no neoliberalismo. Tese (Doutorado) - Programa de Doutorado em Ciências Sociais do Instituto de Filosofia e Ciências Humanas - IFCH, Universidade Estadual de Campinas - Unicamp.

MÉSZÁROS, Istiván. A Educação para além do capital. São Paulo. Boitempo, 2008.

POULANTZAS, Nicos. O Estado, o poder, o socialismo. Rio de Janeiro: Edições Graal, 1980).

VOLPI, Mario. (org.). Regras mínimas das Nações Unidas para a administração da justiça, da infância e da juventude - Regras de Beinjing (In) Adolescentes privados de liberdade. A normativa nacional e internacional e reflexões acerca da responsabilidade penal. São Paulo: Cortez, 2014.

WACQUANT, Loic. As estratégias para cortar os custos do encarceramento em massa nos estados unidos. Novos Estudos. Cebrap, ${ }^{\circ}$ 64, 2002. pp. 53-60.

WAISELFISZ, Julio Jacobo. Mapa da Violência 2013. Homicídios e Juventude no Brasil. Brasília, 2013.

WAISELFISZ, Julio Jacobo. Mapa da Violência 2014. Os jovens do Brasil. Brasília, 2014. 